\title{
Organization Development and Performance: The Impact of ISO 9001:2015, ISO 14001:2015 and OHSAS 18001 Interventions on Product Quality in Manufacturing Organizations of Pakistan
}

\begin{abstract}
Asmat Nawaz Khattak ${ }^{1}$, Muhammad Ilyas²
Abstract

Product quality is a major business dilemma in Pakistan. Organizations are dependent on Organization Development (OD) interventions to help them enhance their product quality to sustain in the global market. OD is a systematic organizational change process. The models of $\mathrm{OD}$ are helpful in designing state-of-the-art production systems to achieve the quality defined by customers. The current mixed methods explanatory sequential research study has tested a mediated model and investigated the impact of three structural OD interventions (ISO 9001:2015, ISO 14001:2015 EO OHSAS 18001) on the product quality. Quantitative data from 146 manufacturing units, collected through a questionnaire, and qualitative data from five management systems experts are merged. Quantitative and qualitative findings show the positive and significant impact of ISO 9001:2015 on the product quality. The quantitative findings show the positive impacts of ISO 14001:2015 and OHSAS 18001 on the product quality. However, the qualitative findings reject any positive contribution of ISO 14001:2015 and OHSAS 18001 in product quality. The findings further revealed that the Integrated Management System (IMS), top management commitment and an effective monitoring system are essential strategies to make the systems more effective and efficient. The paper also discusses the compliant role of high performance corporate culture during the OD change process. The results have implications for corporate managers and management representatives.
\end{abstract}

Keywords: Organization development, integrated management system, corporate culture, product quality and structural OD interventions, ISO 9001:2015, ISO 14001:2015, OHSAS 18001

\section{Introduction}

Low level quality is an unresolved business problem in Pakistan. Kemal (2006) have discussed the "Key issues in Industrial Growth in Pakistan" and highlighted that slow growth rates of productivity and high costs are due to poor quality of products and

1 Superior University, Lahore, Pakistan. E-mail: asmat.khattak@gmail.com

2 Government College Women University, Sialkot, Pakistan. Email: m.ilyas@gcwus.edu.pk

\begin{tabular}{ll} 
ARTICLE HISTORY & \\
3 May, 2018 Submission Received & 30 Jun, 2018 First Review \\
\hline 3 Aug, 2018 Second Review & 28 Nov, 2018 Third Review \\
\hline 8 Dec, 2018 Accepted
\end{tabular}


inefficiencies. Productivity, profitability, revenue and loyalty are not possible without high-quality products. To produce high-quality products, structural OD interventions are the strategic tools in the current business environment. We have examined the impact of three structural OD interventions (ISO 9001:2015, ISO 14001:2015 \& OHSAS 18001) on product quality in the manufacturing organizations of Pakistan.

ISO 9001:2015 certification is an important structural OD intervention and a quality management system. The system help organizations in achieving quality products. Previous research studies have investigated the impact of ISO 9001 intervention on the various aspects of organizational performance (Debby, Vaughan \& Trigunarsyah, 2015; Vasileios \& Odysseas, 2015). Organizations have implemented the ISO 9001 quality system to improve the quality of products (Casadesus \& Karapetrovic, 2005; Corbett, Montes-Sancho \& Kirsch, 2005; Terziovski \& Guerrero, 2014). Furthermore, ISO 9000 certification is an effective structural intervention that leads to enhanced product quality. Debby et al. (2015) stated that many organizations have not achieved the desired performance due to poor management of the certification process. The framework of ISO 9000 changes after each five years. So, there is a need to investigate the impact of ISO 9001:2015 new version on product quality and also to explore the mediating role of the corporate culture.

ISO 14001:2015 is a systematic approach to minimize the negative significant impacts of an activity or operation. ISO 14001:2015 provides a framework for developing an environmental management system for sustainable environmental performance. Research studies have highlighted the various benefits and outcomes of ISO 14001 certification (Vries, Bayramoglu \& Wiele, 2012). Environmental sustainability, operational efficiency, corporate image and enhanced product quality are the potential benefits of ISO 14001 certification (Arena et al., 2012). Puvanasvaran, Tian and Vasu (2014) have integrated lean principles with ISO 14001 to make the system more sustainable, efficient and effective. The certification of ISO 14001 is more beneficial in the presence of high performance corporate culture. Kloepfer (1997) argues that the compatibility of system with the existing corporate culture is essential to achieve the desired benefits. The current study has also investigated the impact of IMS on the product quality.

OHSAS 18001 establishes requirements for occupational health and safety. OHSAS 18001 provides a set of tools that enhance safety risk management and encourage employees to participate in health and safety programs (Puvanasvaran, Tian $\&$ Vasu, 2014). The OHSAS 18001 certification is beneficial to comply legal requirements and to establish production standards (Santos, Barros, Mendes \& Lopes, 2013; Granerud \& Rocha, 2011). The objective of OHSAS 18001 certification is to control occupational health and safety risks, consistent with occupational health and safety 
policy and objectives (OHSAS 18001:2007). OHSAS 18001 enhances the organizational image, goodwill, reputation and performance (Fernandez-Muniz, Montes-Peon \& Vazquez-Ordas, 2012b; Koivupalo, Sulasalmi, Rodrigo \& Vayrynen, 2015).

Corporate culture is a significant aspect of any OD process because it has a major impact on productivity and product quality. A high performance work culture is critical to corporate success (Kelepile, 2015). High performance work culture facilitates the implantation of OD interventions in a better way. On the other hand, research studies have explored that quality management initiatives do not always yield the desired results (Beer, 2003; Rad, 2006). Gambi, Boer, Gerolamo, Jorgensen and Carpinetti (2013) have investigated the relationship between organizational culture and quality techniques and its impact on operational performance and suggest further research studies to develop insight into quality systems and various aspects of organizational culture.

Product quality is a major corporate dilemma because high-quality products are vital to organizational success. Poor quality causes potential sales losses. To achieve quality, business firms need innovative manufacturing processes and programs. The role of state-of-the-art manufacturing programs and tools are now strategic to achieve customer satisfaction (quality) and to enhance safety, health and environmental performances. Structural OD interventions like ISO 9001:2015, ISO 14001:2015 and OHSAS 18001 address various aspects of quality management (Fura, 2013; Koivupalo et al., 2015; Fonseca, 2015; Gaureanu, Weinschrott, Dumitrescu \& Jitarel, 2016; Djofack \& Camacho, 2017). The role of operating and operational procedures is important in improving the quality. Quality related issues are significant in developing countries. The major reason of Pakistan's poor export performance is the low quality products. Pakistan need to upgrade production capabilities and quality (Irfan ul Haque, 2014; Anjum, 2016).

Literature shows few studies on ISO 9001:2015, ISO 14001:2015 and OHSAS 18001 and product quality. The role of corporate culture has not been examined in Pakistani context. The academic world has also ignored the strategic role of OD, ISO Systems and their relationship with product quality. Previous research studies have investigated the isolated role of ISO 9001 (Koh \& Low, 2010; Khanna, 2009; Bhat \& Jagadeesh, 2009; Lau \& Tang, 2009, Zaramdini, 2007), ISO 14001 (Darnall, Henriques $\&$ Sadorsky, 2008) and OHSAS 18001 (Koivupalo et al., 2015) and performance.

This current mixed methods explanatory study has two objectives. The first is to investigate the impact of ISO 9001:2015, ISO 14001:2015 and OHSAS 18001 on product quality in manufacturing organizations in Pakistan. Second significant aspect of the current study is that corporate culture is taken as a mediating variable. 
The findings of this study can be used to understand the nature of impact of ISO 9001:2015, ISO 14001:2015 and OHSAS 18001 on product quality in organizations in Pakistan. Furthermore, how high performance culture accelerate quality management process. The following research questions are formulated.

Research Question 1: What is the nature of the impact of ISO 9001:2015 on product quality in the manufacturing industry of Pakistan?

Research Question 2: What is the nature of the impact of ISO 14001:2015 on product quality in the manufacturing industry of Pakistan?

Research Question 3: What is the nature of the impact of OHSAS 18001 on product quality in the manufacturing industry of Pakistan?

Research Question 4: How corporate culture mediates the relationships of ISO 9001:2015, ISO 14001:2015 and OHSAS 18001and product quality?

\section{Literature Review}

\subsection{OD}

$\mathrm{OD}$ is a process of continuous diagnosis, designing and implementing interventions to improve organizational performance. Beckhard (1969) have defined OD as "an effort that is: 1) planned 2) organization-wide 3) managed from the top 4) increase organization effectiveness and health 5) through planned interventions in the organization's "processes," using behavioral-science knowledge". OD is an organizational change process. The various models of OD are now the emerging tools of performance improvement. Corporate World has already initiated OD interventions to enhance performance at each level. Structural interventions are the re-alignment of the corporate culture, vision, values, strategy, structure and management systems (Khandwalla, 2001). ISO 9001:2015, ISO 14001:2015 and OHSAS 18001 are the three structural interventions. OD is an emerging field in Pakistan. The concepts of OD have not been leveraged to their full potential by the practitioner.

The role of corporate culture is significant during any OD change process. Organizations cannot survive without a high performance work culture, HPWC. HPWC culture facilitates the re-alignment and re-development of management systems and processes.

The remaining section presents a brief discussion on product quality and various ISO standards. Sub-section 2.2 discusses the relationship of ISO 9001:2015 with product quality. Next sub-section 2.3 presents ISO 14001:2015 and subsequently ISO 
18001 discussed in sub-section 2.4 .

\subsection{ISO $9001: 2015$ and product quality}

International Organization for Standardization (ISO) was established in 1947 with the major objectives to develop intellectual, scientific, technological and economic cooperation between the member countries. The head office of ISO is in Geneva, Switzerland. "ISO is an independent, non-governmental international organization with a membership of 162 national standards bodies. ISO develop voluntary, consensus-based, market relevant International Standards that support innovation and provide solutions to global challenges" (ISO Central Secretariat, 2019).

ISO 9001 is an International Standard and its requirements provide a framework for quality management system (QMS). As discussed earlier, quality is a major characteristic to penetrate in the global market. Organizations implement quality programs to achieve products of superior quality. The one objective of quality products is to create delighted customers. The second objective of quality products is to avoid the high cost of poor quality. Organizations should address issues related to preventive costs, appraisal costs, internal failure costs and external failure costs to retain the loyalty. Many organizations have faced lawsuits due to deliveries of poor quality products. Khanna, Laroiyaa \& Sharma (2010) argued that quality in manufacturing process and business excellence attract loyal customers and highlighted that many studies (Koh \& Low, 2010; Khanna, 2009; Kumar, Garg \& Garg, 2009; Bhat \& Jagadeesh, 2009; Lau $\&$ Tang, 2009) have investigated the relationship between quality management and performance. Many quality tools and practices are universal and not industry specific.

Reliable quality products attract global customers. The demands and expectations of customers are changing. ISO 9001:2015 certification ensure product quality and support quality manufacturing programs. ISO 9001:2015 is the latest version of ISO 9000 family which provides requirements for a Quality Management System, QMS. Literature shows many research studies on ISO 9001:2015 and corporate performance (Corbett et al., 2005). ISO 9001:2015 certification guides to achieve product quality. Organizations use ISO 9001:2015 as a benchmark. ISO 9001 certification is a major tool to achieve superior quality (Willar, Vaughan \& Trigunarsyah, 2015; Basir \& Azmi, 2011). Manufacturing industry in Pakistan is implementing ISO 9001:2015 to improve the capabilities of production processes. The QMS helps organizations to produce quality products in a way to better serve the customers. ISO 9001:2015 certification helped organizations to reduce production cost and rejection rate (Ataullah, Sajid \& Khan, 2014; Memon, Abro \& Memon, 2011; Awan, Raouf, Ahmed \& Sparks, 2010).

ISO 9001:2015 is a set of guidelines for the development of a quality management 
system. Literature shows that many organizations are not interested to implement ISO 9001:2015 QMS because the actual change in the entire production system is too expensive and it is difficult to change the work behavior of employees. Organizations feel that the current operational procedures and sub-procedures are working well and no change is required (Nurre, Gunaman \& De-Almeida, 2000). The implantation of the quality program is a systematic process that requires consideration of company's staff and strategy. Organizations should implement and enforce training programs, effective hiring system and total company commitment to continuous commitment (Piskar, 2007). Zaramdini (2007) has stated that ISO 9001 certification is the first step toward quality improvement but organizations should work more for organizational excellence. ISO certification is more beneficial for internal benefits than external ones. Many other studies have also criticized the certification process.

\subsection{ISO 14001:2015 and product quality}

The ISO 14001:2015 provides a comprehensive framework for developing an Environmental Management System, EMS. Objectives and targets' program is developed to minimize and control the negative significant impacts of an activity or operation. The system reduces the harmful impacts and ensures continuous environmental improvement (Christini, Fetsko \& Hendrickson, 2004). ISO 14001:2015 certification is beneficial to improve financial and economic performance. The system also reduces operational costs (Morris, 2003; Dick, Gavin, Saizarbitoria, Inaki \& Molina-Azorin, 2011). According to a report of ISO Central Secretariat (2009), organizations are aware of the need for environmentally friendly behavior. The proactive approach is strategically important for organizations to manufacture products of sustained quality. ISO 14001 family of standards provide tools for environmental performance. Other economic benefits include the reduction of wastages of raw material, energy and also improve process efficiency.

Sroufe (2003) has investigated that there is a need to integrate the cross-function activities and resources to develop an effective and efficient system. Firms have adopted ISO 14001 certification to comply environmental regulations and to manage environmental practices. According to Fura (2013), organizations should establish targets and objectives programs for a maximum performance. ISO 14001:2015 certification improve sales growth and financial results. Many studies have confirmed the positive impact of environmental management system on operational performance, production performance, product quality, process and product innovation (Darnall et al., 2008).

\subsection{OHSAS 18001 and product quality}

Occupational Health and Safety Assessment Series (OHSAS 18001) is a British 
Standard. The standard provides guidelines to identify, control and decrease the risks associated with health and safety at workplace. "Organizations of all kinds are increasingly concerned with achieving and demonstrating sound occupational health and safety $(\mathrm{OH} \& \mathrm{~S})$ performance by controlling their $\mathrm{OH} \& \mathrm{~S}$ risks, consistent with their OH\&S policy and objectives" (OHSAS 18001:2007). Research studies have concluded that OHSAS improve the organizational image, reputation and safety performance. OHSAS 18001 certification positively affect operational efficiency and productivity (Fernandez-Muniz et al., 2012b; Koivupalo et al., 2015). Organizations are interested to adopt OHSAS 18001 as a best practice to improve health and safety performance at workplaces (Idris et al., 2012). However, the findings of many research studies show that adaptation of OHSAS 18001 is less effective. It creates management issues and focuses only on paperwork (Granerud \& Rocha, 2011). A new standard ISO 45001:2018 has been developed to replace OHSAS 18001. ISO 45001:2018 provides requirements for an occupational health and safety $(\mathrm{OH} \& \mathrm{~S})$ management system. The approach of the system is proactive and applicable to any organization.

ISO 9001 is reviewed every five years. The system is revised, if needed. The new version of ISO 9001 is ISO 9001:2015. ISO 9001:2015 helps to assess the organizational risks and opportunities in a better way. Previous research studies have investigated the relationship between ISO 9001 and organizational performance (Piskar, 2007; Willar, et al., 2015; Basir \& Azmi, 2011). The findings of the previous research studies also revealed that ISO 9001 is an important tool to improve quality of products. Many researchers have recommended that ISO 9001 certification is more beneficial for manufacturing industries. The system helps to achieve quality at each level (Willar, et al., 2015; Vaughan \& Trigunarsyah, 2015). Ataullah et al. (2014) have investigated that quality issues resulting in decline in growth of Textile Industry of Pakistan and suggested quality practices to enhance competitiveness. ISO 9000 certification enhances efficiency and reduces customers' complaints and reduces production cost and reject rate (Awan, et. al., 2010; Memon, et al., 2011).

Findings of the previous research studies have also highlighted the ineffective role of ISO 9001 quality management system (Galetto, Franceschini \& Mastrogiacomo, 2017). Previous studies have also ignored the major role of corporate culture in implementing and sustaining the system which is a major gap. We are also interested to investigate the impact of ISO 9001:2015 on product quality in Pakistani context. The current study has tested a mediated model and the following hypotheses were developed in the light of proposed model and previous research studies:

Hypothesis 1: There is a positive relationship between ISO 9001:2015 and corporate culture. 
Hypothesis 2: There is a positive relationship between ISO 9001:2015 and product quality.

Hypothesis 3: There is a positive relationship between corporate culture and product quality.

Hypothesis 4: Corporate culture positively mediates the relationship between ISO 9001:2015 and product quality.

ISO 14001:2015 version is designed to respond to the current industrial trends. The new version also ensures the compatibility with other systems. Pakistan is a fast moving business sector and business managers are not satisfied with the performance of the system. The prime role of ISO 14001 certification is to decrease the negative impacts of operations. However, many studies have also suggested the certification for quality improvement (Fonseca, 2015). Previous research studies have tested the impact of ISO 14001 on the various aspects of corporate performance (Morris, 2003; Dick et al., 2011; Darnall et al., 2008) and to explore the relationship with product quality has been ignored. Research studies recommended that future research should explore the strength of the system in different contexts (Arena et al., 2012). The aim of the current study is to explore the impact of ISO 14001 certificate on product quality in organizations in Pakistan. The current study has used a specific driver of corporate culture that mediates the impact. The findings of the current study will fill the gap of uncertainty about the system. The corporate managers and management representatives will understand the behavior and strength of ISO 14001:2015. In the light of the previous studies, the following hypotheses were developed to be tested:

Hypothesis 5: There is a positive relationship between ISO 14001:2015 and corporate culture.

Hypothesis 6: There is a positive relationship between ISO 14001:2015 and product quality.

Hypothesis 7: Corporate culture positively mediates the relationship between ISO 14001:2015 and product quality.

Research studies are carried out to study the various aspects of Health, Safety and Environment (EHS) in most European countries and their possible relationship with OHSAS 18001 system. Researchers have recommended the system to improve EHS at workplaces (Santos et al., 2013; Fernandez-Muniz et al., 2012b; Koivupalo et al., 2015). Previous studies have also highlighted the important and significant role of OHSAS 18001 in integration with ISO 9001 and ISO 14001(Valadimirovna, 2015). Literature shows rare studies on OHSAS 18001 system and product quality which is 
a major gap. This study aims to identify the benefits of OHSAS 18001 certification especially how the system improve the quality of product and how the corporate culture accelerate the implementation and management of the system which is the ignored area in the previous research studies. In the light of the previous studies, the following hypotheses were developed to be tested:

Hypothesis 8: There is a positive relationship between OHSAS 18001 and corporate culture.

Hypothesis 9: There is a positive relationship between OHSAS 18001 and product quality.

Hypothesis 10: Corporate culture positively mediates the relationship between OHSAS 18001 and product quality.

Figure 1 shows the conceptual framework. There are three independent variables (ISO 9001:2015, ISO 14001:2015 \& OHSAS 18001), one dependent variable (Product Quality) and one is the mediator (Corporate Culture).

\section{Research Methodology}

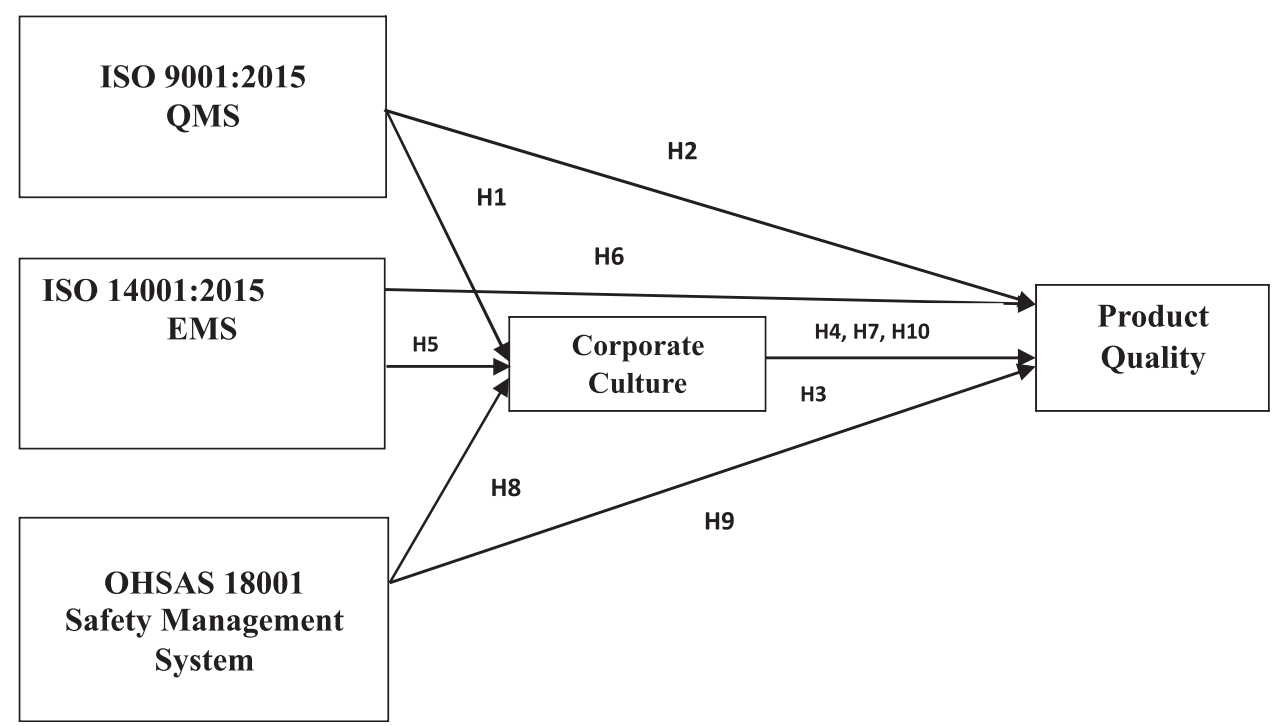

Figure 1: Conceptual Framework of the Research 


\subsection{Research approach}

The mixed methods explanatory sequential research approach is used for the current research study. The design focuses on the completion of the quantitative phase and then the subsequent qualitative phase and the qualitative findings are used to explain the quantitative findings (Creswell, 2003). Mixed methodology is a useful approach to address the challenge of uncertainty during the entire research process (O'Cathain, Murphey \& Nicholl, 2007). Four important dimensions of mixed methodology are participant enrichment, instrument fidelity, treatment integrity and to maximize the significance of the data (Collins, Onwuegbuzie \& Sutton, 2006). The data were merged to achieve useful findings.

\subsection{Population and sampling strategy}

For quantitative study, the population consists of all industrial manufacturing units in Pakistan where ISO 9001:2015, ISO 14001:2015 and OHSAS 18001 systems (IMS) are implemented. The quantitative data was gathered through a random survey from Quality Assurance Managers. The list of industrial units was taken from the office of Bureau VERITAS, Lahore, Pakistan. The list comprised of those industrial units which have implemented the IMS. A sample of 175 industrial manufacturing units was selected using simple random sampling technique. For the qualitative study, a sample of five ISO systems and industrial experts was taken using snowball sampling technique.

\subsection{Instrumentation}

A closed-ended questionnaire is used for the collection of quantitative data. Responses of the participants are obtained on five-point Likert-type Scale (1=strongly disagree to $5=$ strongly agree). A focus group was conducted to discuss and develop a draft and final measurement instrument for this study. The focus group comprised of technical experts in the areas of ISO systems and Management Representatives. Experts review the draft instrument and a final version was developed. Items associated with variables are mentioned in Table 1 .

For qualitative data, face-to-face interviews with five Quality Assurance Managers (QAMs) and Management Representatives (MRs), selected through snow-ball non-probability sampling technique, were conducted and the questions were asked as mentioned in section 1.2. The qualitative study was conducted to explain the quantitative results. Before conducting interviews of the experts, the quantitative results were shared with them. The qualitative data was evaluated and the useful themes were extracted. Findings of quantitative and qualitative studies were integrated and 
Table 1: Items, Variable and Determinants

\begin{tabular}{|c|c|c|c|}
\hline S.no & Variable & Items adopted & Determinants \\
\hline 1. & ISO 9001:2015 & Mangula (2013) & $\begin{array}{c}\text { ISO 9001 certification improve quality and } \\
\text { quantity. Top management commitment, regu- } \\
\text { lar trainings and teamwork are essential aspects } \\
\text { for quality improvement. }\end{array}$ \\
\hline 2. & ISO 14001:2015 & $\begin{array}{c}\text { Arena et al. } \\
(2012)\end{array}$ & $\begin{array}{c}\text { The implementation of ISO 14001 required } \\
\text { considerable investments and sustainability to } \\
\text { ensure competitiveness. Impact on environ- } \\
\text { mental performance and product quality is } \\
\text { positive. }\end{array}$ \\
\hline 3. & OHSAS 18001 & $\begin{array}{c}\text { Gaureanu et al. } \\
(2016)\end{array}$ & $\begin{array}{c}\text { The Integrated Model establishes positive safe- } \\
\text { ty attitude. The goals of quality are achieved. }\end{array}$ \\
\hline 4. & Corporate Culture & Guality management techniques should be \\
(2013) & $\begin{array}{c}\text { Qmplemented according to the cultural charac- } \\
\text { teristics. Quality initiatives based on "one sizes } \\
\text { fit all” is not encouraging philosophy. }\end{array}$ \\
\hline 5. & Product Quality & $\begin{array}{c}\text { Gambi et al. } \\
(2013)\end{array}$ & $\begin{array}{c}\text { Quality techniques improve the quality of the } \\
\text { products. The culture plays the main role. }\end{array}$ \\
\hline
\end{tabular}

Note: This table presents description of items adopted from research studies, variables and determinants associated with independent variables i.e. ISO 9001:2015, ISO 14001:2015, OHSAS 18001, dependent variable i.e. product quality and mediating variable i.e. corporate culture

presented using data merging approach.

\subsection{Data analysis techniques}

The IBM Statistical Package for the Social Sciences (IBM SPSS Statistics) is used for processing and analyzing of the quantitative data. Reliability and internal consistency among items of each construct are determined to check the reliability and internal consistency. Multiple regression analysis is conducted to examine the effect of the bundle of independent variables on mediating variable and the dependent variable. Direct and simple regression analysis is conducted to examine the strength and direction of the relationship between variables. The estimated strength of hypothesized causal relationships is estimated by regression coefficients. The standardized regression coefficient $\beta$ (beta) is determined to calculate the size and direction of the association between variables for significance and to make sure that the conditions of mediation analysis are satisfied as stated by Baron and Kenny (1986). The mediation analysis using Baron and Kenny (1986) method is conducted to check the impact of the mediator on the association of independent variables and dependent variable. Baron and Kenny (1986) proposed a four-step method in which significance of the 
coefficients is determined at each step. Thematic analysis was conducted to analyze the qualitative data and the important themes and ideas were captured. The recorded and transcribed data was processed and analyzed. We applied Braun and Clarke (2006) six-phase guide to analyze the qualitative data.

\section{Results and Analyses}

This section discusses the analysis of the quantitative data in sub-section 4.1, reliability of measures in sub-section 4.2, regression analysis in sub-section 4.3 and the analysis of qualitative data in sub-section 4.4. The quantitative section has explained the demographic profiles of the respondents and presents a descriptive summary. Results and findings of the quantitative study are explained by the qualitative results.

\subsection{Quantitative analysis}

A total of 175 questionnaires were distributed to Quality Assurance Managers of 175 manufacturing industrial units in Pakistan out of which 146 questionnaires were received back. The demographics of participants are presented in Table 2 which contains information related to gender, age, qualifications, total experience in the profession and experience in the organization.

\subsection{Reliability of measures}

Table 2: Demographic Profile of Participants

\begin{tabular}{|c|c|c|}
\hline Demographics & Frequency & Percentage \% \\
\hline Gender (N=146) & & \\
\hline Male & 100 & $68.4 \%$ \\
\hline Female & 46 & $31.5 \%$ \\
\hline Age (N=146) & & \\
\hline Below 25 & 40 & $27.3 \%$ \\
\hline $26-35$ & 06 & $4.1 \%$ \\
\hline $36-45$ & 33 & $22.6 \%$ \\
\hline $46-55$ & 67 & $45.8 \%$ \\
\hline Qualification (N=146) & & \\
\hline MBA & 05 & $3.4 \%$ \\
\hline M. Phil & 30 & $20.5 \%$ \\
\hline M.Sc. Chemistry & 100 & $68.4 \%$ \\
\hline PhD & 00 & $00 \%$ \\
\hline
\end{tabular}




\begin{tabular}{|c|c|c|}
\hline Others & 11 & $7.5 \%$ \\
\hline Total Experience in the Profession(N=146) & & \\
\hline $1-10$ & 31 & $31.2 \%$ \\
\hline $11-20$ & 54 & $41.7 \%$ \\
\hline Above 20 & 61 & \\
\hline Experience in this Organization $(\mathrm{N}=146)$ & & $34.9 \%$ \\
\hline $1-10$ & 51 & $30.1 \%$ \\
\hline $11-20$ & 44 & $34.9 \%$ \\
\hline Above 20 & 51 & $00 \%$ \\
\hline
\end{tabular}

Note: This table presents the demographic profile of participants i.e. gender, age, qualification, total experience in the profession and experience in this organization. Legend: $\mathrm{PhD}$ : Doctor of Philosophy, M.Sc.: Master of Science, M.Phil. Master of Philosophy, MBA: Master of Business Administration

Reliability and internal consistency among items of each construct are determined and the values of Cronbach's alpha are presented in Table 3 which show a high degree of reliability and internal consistency. ISO 9001:2015 (alpha=0.944), ISO 14001:2015 (alpha=0.710), OHSAS 18001 (alpha=0.798), Corporate culture (alpha=0.876) and Product quality (alpha $=0.856$ ).

\subsection{Regression analysis}

Table 3: Reliability of Measurement

\begin{tabular}{|c|c|c|c|}
\hline Constructs & Valid N & Number of Items & Cronbach's alpha \\
\hline ISO 9001:2015 & 146 & 05 & 0.944 \\
\hline ISO 14001:2015 & 146 & 03 & 0.710 \\
\hline OHSAS 18001 & 146 & 03 & 0.798 \\
\hline Corporate Culture & 146 & 04 & 0.876 \\
\hline Product Quality & 146 & 06 & 0.856 \\
\hline
\end{tabular}

Note: This table reports values of Cronbach's alpha of variables

Multiple regression analysis is conducted (see Table 3) to examine the effect of the bundle of the independent variables (ISO 9001:2015, ISO 14001:2015 and OHSAS 18001) on mediating variable (Corporate Culture) and the dependent variable (Product Quality). The standardized regression coefficient $\beta$ (beta) is determined to calculate the size and direction of the association between variables for significance.

Table 7 shows the results of mediation analysis. Direct effects of ISO 9001:2015, 
Table 4: Multiple Regression Analysis

\begin{tabular}{|c|c|c|}
\hline \multirow{2}{*}{ Independent Variables } & \multicolumn{2}{|c|}{ Dependent Variables } \\
\cline { 2 - 3 } & Corporate Culture & Product Quality \\
\hline \multirow{2}{*}{ ISO 9001:2015 } & $0.480^{*}$ & $0.584^{*}$ \\
\cline { 2 - 3 } & $(6.55)$ & $(8.77)$ \\
\hline ISO 14001:2015 & -0.260 & -0.057 \\
\cline { 2 - 3 } & $(-2.872)$ & $(-0.697)$ \\
\hline OHSAS 18001 & $0.438^{*}$ & $0.289^{*}$ \\
\cline { 2 - 3 } & $(5.083)$ & $(3.69)$ \\
\hline Adjusted R & 0.362 & 0.473 \\
\hline F-Statistic & $26.87^{*}$ & $42.49^{*}$ \\
\hline
\end{tabular}

Note: This table presents the results of multiple regression analysis i.e. the aggregate effect of the independent variables (ISO 9001:2015, ISO 14001:2015 and OHSAS 18001) on mediating variable (corporate culture) and the dependent variable (product quality). $\beta^{*}$ represent significance at less than 0.05 , Value in parentheses represents t-ratios

Simple regression analysis is conducted to examine the strength and direction of the relationship between variables.

Table 5: Simple Regression Analysis

\begin{tabular}{|c|c|c|}
\hline \multirow{2}{*}{ Independent Variables } & \multicolumn{2}{|c|}{ Dependent Variables } \\
\cline { 2 - 3 } & Corporate Culture & Product Quality \\
\hline \multirow{2}{*}{ ISO 9001 } & $0.496^{*}$ & $0.640^{*}$ \\
\cline { 2 - 3 } & $(6.85)$ & $(10.00)$ \\
\hline $\mathrm{R}^{2}$ & 0.246 & 0.410 \\
\hline F-statistic & $46.989^{*}$ & $100.078^{*}$ \\
\hline ISO 14001 & $0.208^{*}$ & $0.359^{*}$ \\
\hline & $(2.554)$ & $(4.618)$ \\
\hline R & 0.043 & 0.129 \\
\hline F-statistic & $6.521^{*}$ & $21.330^{*}$ \\
\hline OHSAS 18001 & $0.407^{*}$ & $0.414^{*}$ \\
\cline { 2 - 3 } & $(28.531)$ & $(5.456)$ \\
\hline $\mathrm{R}^{2}$ & 0.165 & 0.171 \\
\hline F-Statistic & $28.531^{*}$ & $29.767^{*}$ \\
\hline
\end{tabular}

Note: This table presents the results of simple regression analysis i.e. the separate effect of the independent variables (ISO 9001:2015, ISO 14001:2015 \& OHSAS 18001) on mediating variable (corporate culture) and the dependent variable (product quality). $\beta^{*}$ represent significance at less than 0.05 , Value in parentheses represents t-ratios 
Table 6: Simple Regression Analysis

\begin{tabular}{|c|c|}
\hline \multirow{2}{*}{ Mediating Variable } & Dependent Variable \\
\cline { 2 - 2 } & Product Quality \\
\hline Corporate Culture & $0.905^{*}$ \\
\cline { 2 - 2 } & $(25.594)$ \\
\hline $\mathrm{R}^{2}$ & 0.820 \\
\hline F-Statistic & $655.043^{*}$ \\
\hline
\end{tabular}

Note: This table presents the results of simple regression analysis i.e. the effect of the mediating variable (corporate culture) on the dependent variable (product quality). $\beta^{*}$ represent significance at less than 0.05 , Value in parentheses represents t-ratios

ISO 14001:2015 and OHSAS 18001 on corporate culture and product quality have been investigated in order to make sure that the conditions of mediation analysis are satisfied as stated by Baron and Kenny (1986). The estimated strength of hypothesized causal relationships is estimated by regression coefficients Results of regression analysis in Table 5 and Table 6 show that the direct effects of ISO 9001 on product quality $(\beta=0.640$, sig. $<0.01)$ and corporate culture $(\beta=0.496$, sig. $<0.01)$ are significant. Similarly, the direct effect of corporate culture on product quality $(\beta=0.905$, sig. $<0.01$ ) is also significant (see Table 6).

Table 7: Mediation Analysis

\begin{tabular}{|c|c|c|c|}
\hline \multirow[t]{2}{*}{ Independent Variables } & \multicolumn{3}{|c|}{ Dependent Variable } \\
\hline & \multicolumn{3}{|c|}{ Product Quality } \\
\hline \multirow[t]{2}{*}{ ISO 9001:2015 } & $0.254^{*}$ & & \\
\hline & $(7.257)$ & & \\
\hline \multirow[t]{2}{*}{ ISO 14001:2015 } & & $0.178^{*}$ & \\
\hline & & (5.394) & \\
\hline \multirow[t]{2}{*}{ OHSAS 18001} & & & 0.055 \\
\hline & & & $(1.419)$ \\
\hline \multirow[t]{2}{*}{ Corporate Culture } & $0.780^{*}$ & $0.868^{*}$ & $0.883^{*}$ \\
\hline & $(22.305)$ & $(26.244)$ & $(22.887)$ \\
\hline Adjusted $\mathrm{R}^{2}$ & 0.868 & 0.850 & 0.822 \\
\hline F-Statistic & $471.347^{*}$ & $405.974^{*}$ & $330.833^{*}$ \\
\hline
\end{tabular}

Note: This table presents the results of the mediation analysis. $\beta^{*}$ Represents significance at less than 0.01 and value in parentheses represents t-rations 


\subsubsection{Analysis for ISO 9001:2015}

Results of regression analysis show that ISO 9001:2015 has a positive and significant effect on corporate culture $(\beta=0.480, p<0.001)$ and product quality. $(\beta=0.584$, $\mathrm{p}<0.001$ ). Results of simple regression analysis in Table 04 show that ISO 9001:2015 is positively and significantly affect corporate culture $(\beta=0.496$, sig. $<0.01)$. The value of $\mathrm{R}^{2}(0.246)$ represents that $24.6 \%$ variation in corporate culture is explained by ISO 9001:2015.The F-statistic (46.989) is significant at less than 1\% significant level which reveals that the model is a good fit. Relationships of ISO 9001:2015 with the product quality is positive and significant. Table 6 shows that the impact of corporate culture ( $\beta=0.905$, sig. $<0.01)$ on product quality is positive and significant. The value of $R^{2}$ $(0.820)$ shows that corporate culture defines the $82 \%$ variation in the product quality. The value of F-statistic (655.343) is significant at less than $1 \%$ significant level which reveals that the model is a good fit.

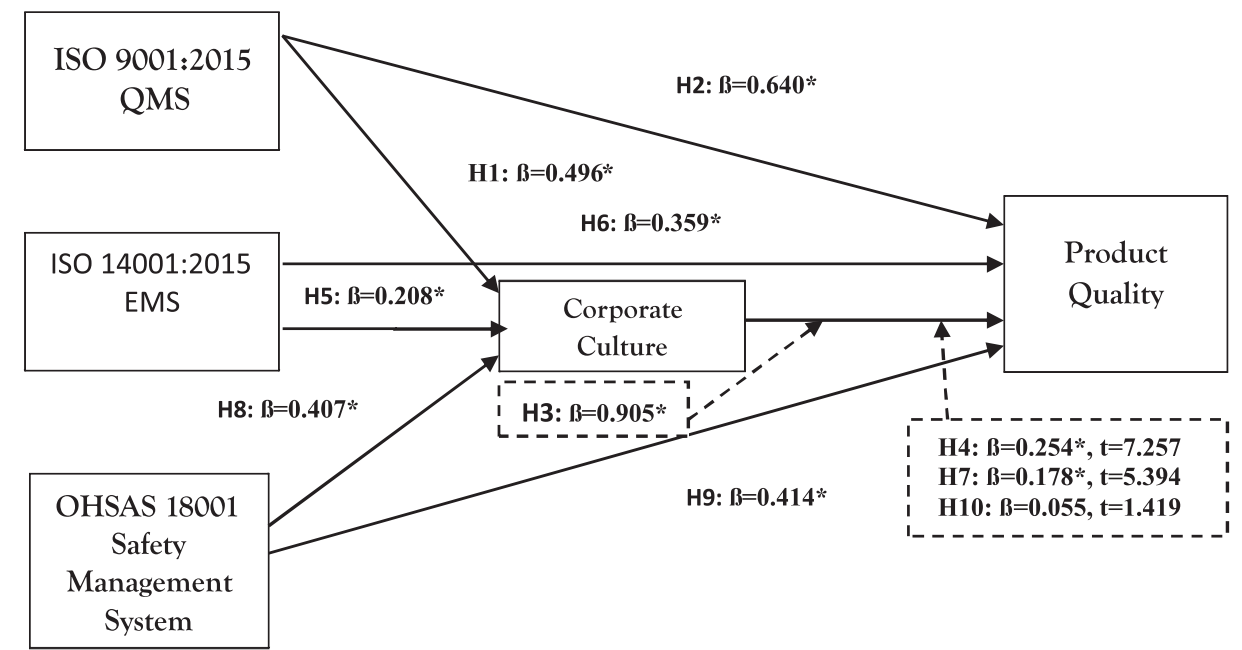

Figure 2: Results of Regression Analysis and Mediation Analysis $\beta^{*}$ Represents significance at less than 0.01 and values of $t$ statistic

Results of mediation analysis in Table 7 show that the indirect effect of ISO 9001:2015 on product quality $(\beta=0.254$, sig. $<0.01)$ is significant and the value of $\beta$ decreases which shows that corporate culture (mediator) partially mediates the relationship between ISO 9001 (independent variable) and the product quality (dependent variable). Partial mediation exists when an independent variable exerts some of its effect on the dependent variable through the mediating variable. Results of regression analysis, Table 5 and Table 6 , and mediation analysis, Table 7, confirmed the mediations and the null hypotheses are rejected and alternate hypotheses $\mathrm{H} 1$, $\mathrm{H} 2, \mathrm{H} 3$ and $\mathrm{H} 4$ are accepted in all cases (see Figure 2). 
Hypothesis 1: There is a positive relationship between ISO 9001:2015 and corporate culture.

Hypothesis 2: There is a positive relationship between ISO 9001:2015 and product quality.

Hypothesis 3: There is a positive relationship between corporate culture and product quality.

Hypothesis 4: Corporate culture positively mediates the relationship between ISO 9001:2015 and product quality.

The results of regressions analysis (Table 5 and Table 6) and mediation analysis (Table 7) indicate the positive and significant association between ISO 9001:2015 and corporate culture, ISO 9001:2015 and product quality, corporate culture and product quality. Corporate culture positively mediates the relationship between ISO 9001:2015 and product quality.

\subsubsection{Analysis for ISO 14001:2015}

The direct effects of ISO 14001:2015 on product quality $(\beta=0.359$, sig. $<0.01)$ and corporate culture $(\beta=0.208$, sig. $<0.01)$ are significant. Similarly, the direct effect of corporate culture on product quality $(\beta=0.905$, sig. $<0.01)$ is also significant (see Table 05 and Table 06). Results of mediation analysis in Table 7 show that the indirect effect of ISO 14001:2015 on product quality $(\beta=0.178$, sig. $<0.01)$ is significant and the value of $\beta$ decreases which shows that corporate culture partially mediates the relationship between ISO 14001:2015 and the product quality. Results of regression analysis (Table 5, Table 6 and Figure 02) and mediation analysis (Table 7) confirmed the partial mediation. So, the null hypotheses are rejected and alternate hypotheses $\mathrm{H} 5, \mathrm{H} 6$ and $\mathrm{H} 7$ are accepted.

Hypothesis 5: There is a positive relationship between ISO 14001:2015 and corporate culture.

Hypothesis 6: There is a positive relationship between ISO 14001:2015 and product quality.

Hypothesis 7: Corporate culture positively mediates the relationship between ISO 14001:2015 and product quality.

The results of regressions analysis (Table 5, Table 6) and mediation analysis (Table 7) show that the impact of ISO 14001:2015 on corporate culture and product quality is positive and significant. Corporate culture positively mediates the relationship 
between ISO 14001:2015 and product quality.

\subsubsection{Analysis for OHSAS 18001}

The direct association of OHSAS 18001 with product quality $(\beta=0.414$, sig. $<0.01)$ and corporate culture $(\beta=0.407$, sig. $<0.01)$ are positive and significant. However, the indirect relationship of OHSAS 18001 with product quality $(\beta=0.055, t=1.419$, sig. $=0.158)$ is insignificant which shows that corporate culture fully mediates the relationship between OHSAS 18001 and the product quality. Results of regression analysis (Table 5 and Table 6), and mediation analysis (Table 7) confirmed the mediations and the null hypotheses are rejected and the below alternate hypotheses $\mathrm{H} 8$, $\mathrm{H} 9$ and $\mathrm{H} 10$ are accepted.

Hypothesis 8: There is a positive relationship between OHSAS 18001 and corporate culture.

Hypothesis 9: There is a positive relationship between OHSAS 18001 and product quality.

Hypothesis 10: Corporate culture positively mediates the relationship between OHSAS 18001 and product quality.

The quantitative analysis establishes the positive relationship between OHSAS 18001 and corporate culture and product quality. Corporate culture positively mediates the relationship between OHSAS 18001 and product quality.

\subsection{Qualitative data analysis}

Thematic analyses are conducted to analyze the qualitative data. Various significant themes of the transcribed data are captured and presented below.

Research Question 1: What is the nature of the impact of ISO 9001:2015 on product quality in the manufacturing industry of Pakistan?

Experts shared that ISO 9001:2015 is an important structural intervention and organizations have adopted ISO 9001:2015 to improve the quality dimensions. ISO 9001:2015 has presented a framework for product realization from design to delivery. The focus of the new version ISO 9001:2015 is to enhance the application of process approach. The positive impact of ISO 9001:2015 and other quality management systems on the product quality has been accepted globally. However, organizations should address the issues of system sustainability. A comprehensive corporate strategy, management commitment, strong internal control are organizational aspects that make the system more effective and efficient. 
Research Questions 2: What is the nature of the impact of ISO 14001:2015 on product quality in the manufacturing industry of Pakistan?

ISO 14001:2015 focuses on efficient utilization of organizational resources, control of wastages, and continual improvement. The system ensure the better environmental performance of organizational components to gain strategic business objectives. The impact of ISO 14001:2015 on product quality is not encouraging. However, the requirements of the system are development to minimize the negative significant impacts of aspects in organizations. The system has a little contribution to improving the product quality. The role of certification, monitoring, and regulatory bodies is instrumental to implement a strong check and reviewing procedures. The system has yield better results in Multi-National Corporations due to well-defined processes, visionary leadership and commitment.

Research Questions 3: What is the nature of the impact of OHSAS 18001 on product quality in the manufacturing industry of Pakistan?

Experts pointed out that OHSAS 18001 provides a framework for structured approach. The system focuses on commitment to health, safety and business performance. The requirements of the system are developed to keep a workplace safe and productive. The association between OHSAS 18001 and product quality is debatable and not encouraging. However, the integration of ISO 9001:2015, ISO 14001:2015 and OHSAS 18001 demonstrates positive impact on product quality.

\section{Conclusions}

The major objective of the current research study was to explore the impact of three structural OD interventions (ISO 9001:2015, ISO 14001:2015 \& OHSAS 18001) on product quality in the manufacturing industries of Pakistan. Findings and results of the research study are presented in this section. Sub-section 5.1 explain the nature of impact of ISO 9001:2015 on product quality, sub-section 5.1 highlighted the nature of impact of ISO 14001:2015 on product quality, sub-section 5.3 explain the nature of impact of OHSAS 18001 on product quality and sub-section 5.4 elaborate how corporate culture mediates the relationships of ISO 9001:2015, ISO 14001:2015 and OHSAS 18001and product quality?

\subsection{ISO $9001: 2015$ and product quality}

The quantitative findings indicate that the impact of ISO 9001:2015 on product quality is positive and significant. Product quality receives maximum impact from ISO 9001:2015. Previous research studies also revealed that ISO 9001 is a strategic tool and used to help organizations to minimize cost of production, rejections and to 
improve quality. The impact of ISO 9001 certification on product quality is positive and encouraging. ISO 9001 certification is more suitable for manufacturing industries to improve product quality and performance (Willar, et al., 2015; Ataullah, et al., 2014; Vasileios \& Odysseas, 2015; Debby, Vaughan \& Trigunarsyah, 2015).

Many research studies have also highlighted the ineffective role of ISO 9001 certification (Debby, Vaughan \& Trigunarsyah, 2015; Galetto et al., 2017). According to the claim of experts of the qualitative study, ISO 9001:2015 is a systematic way of achieving organizational excellence. Sustainability of the system is a major issue in Pakistan. The effective and efficient system requires a comprehensive corporate strategy aligned with the business strategy. The success of any quality program depends upon the level of management commitment and a rich business culture accelerates quality programs. ISO 9001:2015 certification is fruitful if the set of quality standards are implemented and maintained in the true sense. The process needs a commitment from top to bottom. Findings show that Pakistani firms acquired the ISO 9001:2015 certification as result of external pressure. Firms are not interested to develop a culture of quality and excellence. In Pakistan, another issue is the commitment of top management. Saleem et al. (2011) have examined the impact of ISO 9000 on organizational performance in Pakistan and highlighted the low commitment of management. Successful implementation of the system is not possible without the top management commitment. Shafiq (2012) has studied the role of quality management systems in textile sector of Pakistan and stated that ISO 9000 is widely adopted by textile manufacturers. Firms need to integrate the system with other management systems to achieve better performance.

Organizations wishing to improve product quality need to develop a strong internal and monitoring system. Quality Assurance experts recommended ISO 9001:2015 certification for both internal and external benefits. However, Djofack and Camacho (2017) say that organizations prefer ISO 9001:2015 certification to achieve internal benefits like processes, procedures and the product quality. In Pakistan, firms fail to achieve the desired results from any quality program due to lack of professionalism, lack of quality attitudes of the employees and poor cooperative culture

\subsection{ISO $14001: 2015$ and product quality}

The quantitative findings of the current study show positive and significant impact of ISO 14001:2015 on product quality. Previous research studies also have investigated the impact of ISO 14001 on various aspects of performance. According to Fura (2013) and Fonseca (2015), ISO 14001 reduces negative impacts; improve financial and economic performance, improve product quality and reduces operational costs. 
Experts of the qualitative study stated that the prime objectives of ISO 14001:2015 certification are to control industrial wastages and environmental hazards. The certification helps organizations to do business in the global market. On the other hand, organizations in Pakistan have adopted ISO 14001:2015 to qualify external audits requirements. The impact of ISO 14001:2015 on product quality is not encouraging. The system has a little contribution to improving the product quality. Organizations are not penalized for their poor operational and environmental procedures. Organizations are not interested to move forward to adopt a systematic approach to control industrial effluents. However, the system has enhanced many aspects of the quality in Multi-National Corporations.

Anjum and Imran Ullah (2016) have discussed the trends and scope of ISO certification in Pakistan and highlighted the main drivers. Globalization is a major challenge. Compliance to quality is also a major business dilemma. If we compare Pakistan with developed countries, Pakistan need more environmental sustainability to achieve the corporate objectives. Currently, organizations are not interested to develop the capacity to minimize the negative operational impacts. Organizations need more work to develop green culture.

\subsection{ISO OHSAS and product quality}

The quantitative findings of the current study reveal that the direct association of OHSAS 18001 between the product quality is significant. Previous research studies have also explained the nature of the association between OHSAH 18001 and various performance parameters. OHSAS 18001 certification improve productivity and encourages employees to attend health and safety programs (Gaureanu et al., 2016; Koivupalo et al., 2015). The views of the Quality Assurance Managers are worth mentioning. They shared their views that the objectives of OHSAS 18001 certification are to reduce the risk of accidents and to promote the safety culture. In Pakistan, incident cases are not reported. Although, OHSAS 18001 provides a framework to mitigate the potential risks at workplaces (Ehsan, Anwar \& Talha, 2009). Experts stated that the direct link between OHSAS 18001 and product quality is not encouraging. Employees of the manufacturing organizations face many health and safety challenges. The majority of workers lack knowledge about health and safety issues in Pakistan. The incidents rate at workplaces is high. Organizations should incorporate green practices and innovative technologies to promote health and safety culture. Ineffective legislations and weak enforcement are the major aspects of poor health and safety situation in Pakistan (Hassan, 2012). Generally, OHSAS 18001 certification promotes safety culture and improves operational control that leads to an effective manufacturing process and product storage. 
Experts also recommend the integration of ISO 9001:2015, ISO 14001:2015 and OHSAS 18001 into a single Integrated Management System (IMS). The integrated models are more helpful in organization development. Previous research studies also revealed that IMS reduces cost and helps to improve operations. The IMS model enhances the efficiency of multiple functions. However, training and development of top management on integration issues is mandatory (Dahlin \& Isaksson, 2017; Ismyrlis, 2017; Domingues, Sampaio \& Arezes, 2017).

\subsection{The mediation role of corporate culture}

The second objective of the current study was to investigate the role of high performance culture in implementing and sustaining of ISO 9001:2015, ISO 14001:2015 and OHSAS 18001 systems. The findings of the current study concluded the strategic and compliant role of the corporate culture. Corporate culture partially mediates the association of ISO 9001:2015 and ISO 14001:2015 with the product quality. Corporate culture fully mediates the relationship of OHSAS 18001 with the product quality. Results show that high-performance corporate culture facilitates the implementation of OD initiatives and quality improvement efforts. Corporate culture plays a major role in any OD change process. A high-performance culture is a set of behaviors. Behaviors are applied within organizations to achieve superior objectives. A culture where employees gain the clarity on corporate business interests. A high performance culture accelerate the performance because employee share knowledge and innovative ideas. Employees know their responsibilities and goals and they are rewarded for achievements. High performance culture is one of the major drivers of any management process. However, the components of a high performance work culture are unique to each company.

\section{Limitations and Future Research Directions}

Findings of this research study are limited by its focus and scale. This research study has utilized a mixed methods explanatory design which is a costly and lengthy process. Further research should extend the study to cover other methodologies to explore the phenomena in more detail. However, the design enhanced the worth of findings. As discussed, OD is an emerging field in Pakistan and still organizations have not achieved the sustained benefits from ISO certification. Research studies on $\mathrm{OD}$, ISO systems and corporate culture are rare. In literature, qualitative research studies on the topic are uncommon.

The results of the current research study provide valuable contributions to theory and practice and will create knowledge in the area of "OD structural interventions" in Pakistan. Findings are also beneficial for corporate managers, policy makers and 
Management Representatives (MRs) to design and implement ISO systems for quality improvement. The study is more strategic in nature and will encourage research on OD and ISO systems in Pakistan. Findings of the current study provide empirical support that structural interventions, aligned with high-performance work culture, are helpful to achieve high quality products.

\section{References}

Arena, M., Azzone, G., \& Platti, M. (2012). ISO14001: Motivations and benefits in the Italian metal industry. International Journal of Engineering Business Management, 4(41), 1-9.

Anjum, M. N., \& Imran Ullah (2016). ISO certifications: Trends and scope in Pakistan. European Journal of Business and Management, 8(10), 81-89.

Anjum, U., Aftab, J., Sultan, Q.-u.-A., \& Ahmed, M. (2016). Factors affecting the service quality and customer satisfaction in telecom industry of Pakistan. International Journal of Management, Accounting and Economics, 3(9), 509-520.

Ataullah, M. A., Sajid, A., \& Khan, M. R. (2014). Quality related issues and their effect on return of Pakistan textile industry. Journal of Quality and Technology Management, X(1), 69-91.

Awan, M. U., Raouf, A., Ahmed, N., \& Sparks, L. (2010). Total quality management in developing countries: A case of pharmaceutical wholesale distribution in Pakistan. International Journal of Pharmaceutical and Health Care Marketing, 3(4), 363-380.

Baron, R. M., \& Kenny, D. A. (1986). The moderator-mediator variable distinction in social psychological research: Conceptual, strategic and statistical considerations. Journal of Personality and Social Psychology, 51(6), 1173-1182.

Beer, M. (2003). Why TQM programs do not persist: The role of management quality and implications for leading a TQM transformation. Decision Sciences, 34(4), 623-642.

Beckhard, R. (1969). Organization development: Strategies and models. Reading, Mass: Addison-Wesley

Basir, S. A., \& Azmi, I. A. G. (2011). Malaysian Islamic quality management system MS 1900 from an Islamic perspective: An implementation model. Journal of Shari'ah, University Malaya Press, 19(2), 85-106.

Bhat, K. S., \& Jagadeesh, R. (2009). An empirical study of barriers to TQM implementation in Indian industries. The TQM Magazine, 219(3), 261-272.

Boer, H., Gerolamo, M. C., Jorgensen, F., \& Carpinetti, L. C. R. (2015). The relationship between organizational culture and quality techniques, and its impact on operational performance. International Journal of Operations $\mathcal{E}$ Production Management, 35(10), 1460-1484.

Braun, V., \& Clarke, V. (2006). Using thematic analysis in psychology. Qualitative Research in Psychology, 
3, 77-101.

Casadesus, M., \& Karapetrovic, S. (2005). Has ISO 9000 lost some of its luster? A longitudinal impact study. International Journal of Operations \& Production, 25(6), 580-596.

Christini, G., Fetsko, M., \& Hendrickson, C. (2004). Environmental management systems and ISO 14001 certification for construction firms. Journal of Construction Engineering and Management, 130(3), 330-336.

Corbett, C., Montes-Sancho, M. J., \& Kirsch, D. A. (2005). The financial impact of ISO 9000 certification in the United States: An empirical analysis. Management Sciences, 51(7), 1046-1059.

Collins, K. M. T., Onwuegbuzie, A. J., \& Sutton, I. L. (2006). A model incorporating the rationale and purpose for conducting mixed methods research in special education and beyond. Learning disabilities: A Contemporary Journal, 4(1), 67-100.

Creswell, J. W. (2003). Research design: Qualitative, quantitative and mixed methods approach (2nd Ed.). Thousand Oaks, CA: SAGE Publications.

Darnall, N., Henriques, I., \& Sadorsky, P. (2008). Do environmental management systems improve business performance in an international setting? Journal of International Management, 14(4), 364-376.

Debby, W., Vaughan, C., \& Trigunarsyah, B. (2015). Examining the implementation of ISO 9001 in Indonesian construction companies. The TQM Journal, 27(1), 94-107.

Dick, Gavin, P.M., Saizarbitoria, H., Inaki, \& Molina-Azorin, J. F. (2011). ISO 14001 certification and financial performance: Selection-effect versus treatment-effect. Journal of Cleaner Production, 19 (1), 1-12.

Dahlin, G., \& Isaksson, R. (2017). Integrated management systems - interpretations, results, opportunities. The TQM Journal, 29(3), 528-542.

Djofack, S., \& Camacho, M. A. C. (2017). Implementation of ISO 9001 in the Spanish tourism industry. International Journal of Quality $\mathcal{E}$ Reliability Management, 34(1), 18-37.

Domingues, P., Sampaio, P., \& Arezes, P. M. (2017). Management systems integration: Survey results. International Journal of Quality E Reliability Management, 34(8), 1252-1294.

Ehsan, N, Anwar, S., \& Talha, M. (2009). Professional ethics in construction industry of Pakistan [Online] World Congress on Engineering 1. Available at: http:// www.iaeng.org/publication/WCE2009/ WCE2009_729-733.pd

Fernandez-Muniz, B., Montes-Peon, J. M., \& Vazquez-Ordas, C. J. (2012b). Safety climate in OHSAS 18001-certified organisations: Antecedents and consequences of safety behavior. Accident Analysis and Prevention, 45, 745-758.

Fonseca, L. (2015). ISO 14001:2015: An improved tool for sustainability. Journal of Industrial Engineering and Management, 8(1), 37-50. 
Fura, B. (2013). Improving ISO 14001 environmental management systems. Polish Journal of Environmental Studies, 22(6), 1711-1721.

Gambi, L. D. N., Boer, H., Gerolamo, M. C., Jorgensen, F., \& Carpinetti, L. C. R (2013). The relationship between organizational culture and quality techniques, and its impact on operational performance. International Journal of Operations $\mathcal{E}$ Production Management, 35(10), 1460-1484.

Gaureanu, A., Weinschrott, H., Dumitrescu, C. D., \& Jitarel, A. (2016). Quality management and occupational safety and health effects on organization's sustainable development, Managing innovation and diversity in knowledge society through turbulent time, presented at MakeLearn \& TIIM conference, Timisoara City, 2016, Timisoara, Romania: ToKnowPress.

Granerud, L., \& Rocha, R. S. (2011). Organizational learning and continuous improvement of health and safety in certified manufacturers. Safety Science, 49(2011), 1030-1039.

Galetto, M., Franceschini, F., \& Mastrogiacomo, L. (2017). ISO 9001 certification and corporate performance of Italian companies. International Journal of Quality $\mathcal{E}$ Reliability Management, 34(2), 231-250.

Hassan, S. A. (2012). Health, safety and environmental practices in the construction sector of Pakistan (Master's Thesis). Uppsala University, Department of Earth Sciences

ISO Central Secretariat (2009). Environmental management: The ISO 14000 family of international standards, Switzerland.

ISO Central Secretariat (2019). The ISO 9001 family of international standards, Switzerland. https:// www.iso.org/about-us.html. Retrieved on January 4, 2019.

Idris, M. A., Ab Aziz, N. F., \& Zailee, S. (2012). The adoption of management systems standards \& best practices in Malaysia. Nang Yan Business Journal, 2(5), 105-112.

Irfan ul Haque (2014). Toward a competitive Pakistan: The role of industrial policy. The Lahore Journal of Economics, 19, 61-90.

Ismyrlis, V. (2017). The contribution of quality tools and integration of quality management systems to the organization. The TQM Journal, 29(5), 677-689.

Kelepile, K. (2015). Impact of organizational culture on productivity and quality management: A case study in diamond operations unit, DTC Botswana. International Journal of Research in Business Studies and Management, 2(9), 35-45.

Kemal, A. R. (2006). Key issues in industrial growth in Pakistan. Lahore Journal of Economics, 11(Special E), $49-74$.

Khanna, H. K., Laroiyaa, S. C., \& Sharma, D. D. (2010). Quality management in Indian manufacturing organizations: Some observations and results from a pilot survey. Brazilian Journal of Operations $\mathbb{E}$ Production Management, 7(1), 141-162.

Khanna, V. K. (2009). 5 "S" and TQM status in Indian organizations. The TQM Journal, 21(5), 486-501. 
Khandawala, P.N. 2001. Turnaround excellence, insights from 120 cases, Response Books, India.

Koh, T. W., \& Low, S. P. (2010). An empiricist framework for TQM implementation in construction companies. Journal of Management in Engineering, 24(3), 133-143.

Koivupalo, M., Sulasalmi, M., Rodrigo, P., \& Vayrynen, S. (2015). Health and safety management in a changing organization: Case study global steel company. Safety Science, 74, 128-139.

Kloepfer, R. J. (1997). Will the real ISO 14001 please stand up? Civil Engineering, 67(11), 45-47.

Kumar, R., Garg, D., \& Garg, T. K. (2009). Total quality management in Indian industries: Relevance, analysis and directions. The TQM Journal, 21(6), 607-622.

Lau, A. W. T., \& Tang, S. L. (2009). A survey on the advancement of QA (quality assurance) to TQM (total quality management) for construction contractors in Hong Kong. International Journal of Quality $\mathcal{E}$ Reliability Management, 26(5), 410-425.

Memon, N. H., Abro, Q. M., \& Memon, Z. A. (2011). ISO in the construction and manufacturing companies: A case study from the construction industry of Hyderabad and Karachi, Pakistan. Mehran University Research Journal of Engineering EF Technology, 30(2), 339-348.

Morris, A. S. (2003). ISO 14000 Environmental management standards: Engineering $\mathcal{E}$ financial aspects. John Wiley, London.

Mangula, M. S. (2013). Effect of quality management systems (ISO 9001) certification on organizational performance in Tanzania: A case of manufacturing industries in Morogoro. International Journal of Technology Enhancement $\mathcal{E}$ Emerging Engineering Research, 1(1), 14-19.

Nurre, A., Gunaman, Y., \& De-Almeida, D. (2000). What it means to be ISO 9000 certified, 3-4. Philippine institute for development studies. Retrieved from http://www.pids.gov.ph.

OHSAS Project Group (2007). Occupational health and safety management systems - requirements. Retrieved from: http://www.aims.org.pk/wp-content/uploads /2014/ 08/OHSAS-18001-2007-Standards.pdf

O'Cathain, A., Murphey, E., \& Nicholl, J. (2007). Integration and publications as indicators of "yield" from mixed methods studies. Journal of Mixed Methods Research, 1(2), 147-163.

Piskar, F. (2007). The impact of the quality management system ISO-9000 on customer satisfaction of Slovenian companies. Managing Global Transitions, 5(1), 45-61.

Puvanasvaran, P., Tian, R. K. S., \& Vasu, S. (2014). Lean environmental management integration system for sustainability of ISO 14001:2004 standard implementation. Journal of Industrial Engineering and Management, 7(5), 1124-1144.

Rad, A. M. M. (2006).The impact of organizational culture on the successful implementation of total quality management, The TQM Magazine, 18(6), 606-625.

Santos, G., Barros, S., Mendes, F., \& Lopes, N. (2013). The main benefits associated with health and 
safety management systems certification in Portuguese small and medium enterprises post quality management system certification. Safety Science, 51(1), 29-36.

Saleem, I., Siddique, I., Akmal, A., Khan, M. S. M., Khan, M. U., \& Sultan, S. (2011). Impact assessment of ISO 9000 series on organizational performance: Empirical evidence from small and medium enterprises (SME) sector of Pakistan. African Journal of Business Management, 5(26), 10885-10892.

Sroufe, R. (2003). Effect of environmental management systems on environmental management systems and operations. Production and Operation Management, 12(3), 416-431.

Shafiq, M. (2012). Implementation of quality management systems and business excellence frameworks in Pakistani textile companies. Journal of Quality E Technology Management, VIII(II), 11-23.

Terziovski, M., \& Guerrero, J. L. (2014). ISO 9000 quality system certification and its impact on product and process innovation performance. Int. J. Production Economics, 158, 197-207.

Texeira Quiros, J., Almaca, J. A., \& Fernandes Justino, M. R. (2010). How quality affects the bottom line? A literature review. Intangible Capital, 6(2), 258-271.

Vasileios, I., \& Odysseas, M. (2015). The effects of ISO 9001 certification on the performance of Greek companies: A multidimensional statistical analysis. The TQM Journal, 27(1), 150-162.

Vries, H. J, de, Bayramoglu, D. K., \& Wiele, T., V, der, (2012). Business and environmental impact of ISO 14001. International Journal of Quality and Reliability Management, 29(4), 425-435.

Valadimirovna, E. E. (2015). Approaches to implementation of an integrated management system in the pharmaceutical industry. Galenical pharmaceutical production. International Journal for Quality Research, 9(3), 527-546.

Willar, D., Vaughan, Q., \& Trigunarsyah, C. B. (2015). Examining the implementation of ISO 9001 in Indonesian construction companies. The TQM Journal, 27(1), 94-107.

Zaramdini, W. (2007). An empirical study of the motives and benefits of ISO 9000 certification: the UAE experience. International Journal of Quality $\mathcal{E}$ Reliability Management, 24(5), 472-491. 
